\title{
Rituximab in addition to LMB-based chemotherapy regimen in children and adolescents with primary mediastinal large B-cell lymphoma: results of the French LMB2001 prospective study
}

Marie Emilie Dourthe, ${ }^{1,2}$ Aurélie Phulpin, ${ }^{3}$ Anne Auperin, ${ }^{4}$ Jacques Bosq, ${ }^{5}$ Marie-Laure Couec, ${ }^{6}$ Peggy Dartigues, ${ }^{5}$ Stéphane Ducassou, ${ }^{7}$ Nathalie Garnier, ${ }^{8}$ Stéphanie Haouy, ${ }^{9}$ Thierry Leblanc, ${ }^{2}$ Amaury Leruste, ${ }^{10}$ Catherine Paillard, ${ }^{11}$ Charlotte Rigaud, ${ }^{12}$ Mathieu Simonin, ${ }^{2,13}$ Catherine Patte ${ }^{12}$ and Véronique Minard-Colin ${ }^{12,14}$

\footnotetext{
'Department of Pediatric Hematology and Immunology, Robert Debré University Hospital, APHP and University de Paris, Paris; ${ }^{2}$ Université de Paris, Institut Necker-Enfants Malades (INEM), Institut National de la Santé et de la Recherche Médicale, INSERM U1151, and Laboratory of Onco-Hematology, Assistance Publique-Hôpitaux de Paris, Hôpital Necker Enfants-Malades, Paris; ${ }^{3}$ Pediatric Oncology and Hematology Department, University Hospital of Nancy (CHRU Nancy), Nancy; ${ }^{4}$ Service de Biostatistique et d'Epidémiologie, Gustave Roussy Cancer Campus, INSERM U1018, CESP, Université Paris-Sud, Université Paris-Saclay, Villejuif ; ${ }^{5}$ Department of Biopathology, Morphology Unit, Gustave Roussy, Université Paris Saclay, Villejuif; ${ }^{6}$ Department of Pediatric Hematology and Oncology, University Hospital of Nantes, Nantes; ${ }^{7}$ Department of Pediatric Oncology and Hematology, University Hospital of Bordeaux, Bordeaux; ${ }^{8}$ Institut d'Hématologie et d'Oncologie Pédiatrique, Hospices Civils de Lyon, Lyon; ${ }^{9}$ Department of Pediatric Oncology and Hematology, University Hospital of Montpellier, Montpellier; ${ }^{10}$ SIREDO Oncology Center, Institute Curie, PSL Research University, Paris; ${ }^{11}$ Department of Pediatric Hematology Oncology, University Hospital of Strasbourg, INSERM UMRS 1109, Strasbourg; ${ }^{12}$ Department of Pediatric and Adolescent Oncology, Gustave Roussy, Université Paris-Saclay, Villejuif; ${ }^{13}$ Pediatric Hematology Oncology Department, Sorbonne Université/Trousseau Hospital, AP-HP, Paris and ${ }^{14}$ Gustave Roussy and Paris-Saclay University, INSERM 1015, Paris, France
}

\author{
Correspondence: \\ $M-E$. Dourthe \\ marie-emilie.dourthe@aphp.fr \\ V. Minard-Colin \\ veronique.minard@gustaveroussy.fr \\ Received: $\quad$ October $27,2021$. \\ Accepted: $\quad$ February 23, 2022. \\ Prepublished: March 3, 2022. \\ https://doi.org/10.3324/haematol.2021.280257 \\ ○2022 Ferrata Storti Foundation \\ Published under a CC BY-NC license @@ (1)
}

\begin{abstract}
Primary mediastinal large B-cell lymphoma (PMLBL) is a rare entity predominantly affecting adolescents and young adults. Recently, an international phase $\|$ trial in pediatric patients using dose-adjusted etoposide, doxorubicin, and cyclophosphamide with vincristine and prednisone plus rituximab (DA-EPOCH-R) failed to reproduce excellent survival reported in some adult studies. The optimal therapy regimen needs to be determined in this disease. The French prospective LMB2001 trial included all patients $\leq 18$ years with mature B-cell lymphoma treated in French centers. For patients with PMLBL, treatment included four to eight courses of Lymphomes Malins B (LMB)-based chemotherapy without radiotherapy. From 2008, rituximab was added before each chemotherapy course. From 09/2001 to 03/2012, 42 patients with PMLBL were registered. The median age was 15 years (range, 8-18). Twenty-one patients were treated with chemotherapy plus rituximab. The median follow-up was 7.1 years (interquartile range, 5.8-11.1). Five-year event-free and overall survival were $88.1 \%$ (95\% confidence interval $(\mathrm{Cl}): 75.0-94.8)$ and $95.2 \%(95 \% \mathrm{Cl}: 84.0-98.7)$ for the whole population. The 5-year EFS was $81.0 \%$ (95\% Cl: 60.0-92.3) and 95.2\% (95\% Cl: $77.3-99.2)$ (hazard ratio $=0.24 ; 95 \% \mathrm{Cl}$ : $0.03-$ 2.2) and 5 -year overall survival was $90.5 \%(95 \% \mathrm{Cl}: 71.1-97.3)$ and $100 \%$ for patients treated without and with rituximab, respectively. Only one of 21 patients treated with rituximab and LMB-based chemotherapy had local early treatment failure but achieved prolonged complete remission with second-line chemotherapy and radiotherapy. Intensive LMBbased chemotherapy with rituximab achieved excellent survival in children/adolescents with PMLBL. Further international prospective studies are required to confirm these results in this population.
\end{abstract}

\section{Introduction}

Primary mediastinal (thymic) large B-cell lymphoma
(PMLBL) is a distinct pathogenetic subtype of mature Bcell neoplasms. ${ }^{1}$ It is a rare entity representing $2-4 \%$ of adult and pediatric non-Hodgkin lymphoma. ${ }^{2,3}$ PMLBL 
most commonly presents in female adolescents and young adults with signs and symptoms of bulky mediastinal disease. It is biologically related to nodular sclerosis Hodgkin lymphoma on pathology and gene expression profiling although some phenotype markers (MUM1, MAL), ${ }^{4}$ as well as lactate dehydrogenase (LDH) levels and 18fluorodeoxyglucose-positron emission tomography/ computed tomography (18F-FDG PET/CT) findings help discriminate mediastinal Hodgkin lymphoma from PMLBL. ${ }^{5}$ In adults with PMLBL, although there is a lack of consensus about the optimal therapeutic strategy for newly diagnosed patients, highly curative strategies, including rituximab, cyclophosphamide, doxorubicin, vincristine and prednisone (R-CHOP) and dose-adjusted etoposide, doxorubicin, and cyclophosphamide with vincristine and prednisone plus rituximab (DA-EPOCH-R) are mainly recommended. ${ }^{6}$ However, significant cumulative doses of chemotherapy are achieved with both chemotherapy regimens and a substantial rate of patients still need radiation therapy (RT), especially with R-CHOP.

In children and adolescents, the first prospective international phase II study of DA-EPOCH-R regimen ${ }^{7}$ failed to reproduce the outstanding survival reported with this regimen in some adults studies. Treatment strategies originally designed for Burkitt lymphoma are successfully used for children with diffuse large B-cell lymphoma (DLBCL) $)^{8,9}$ but patients with PMLBL presented more aggressive disease and specific approaches were needed. ${ }^{10,11}$ Herein, we reported the experience of the prospective French LMB 2001 study with 42 PMLBL patients treated with intensive LMB-based chemotherapy between 09/2001 and 03/2012, with the addition of rituximab from 2008.

\section{Methods}

\section{Diagnosis, classification and staging}

The French LMB 2001 prospective study included patients less or equal to 18 years old, with mature B-cell lymphoma including PMLBL. Patients with known pre-existing immunodeficiency were not included. For the purpose of this analysis, pathology was planned to be reviewed by national experts for diagnosis as PMLBL. The LMB2001 study has been approved by the SFCE Scientific Committee and National Ethics Committee. Parents/legal guardians provided written informed consent for the inclusion of their children in the studies in accordance with the Declaration of Helsinki. Minimal work-up included clinical examination, chest $\mathrm{x}$-ray, abdominal ultrasound or CT, two bone marrow (BM) aspirates and biopsies, cerebrospinal fluid (CSF) cytology, and standard blood analysis including LDH level ( $\leq$ or $>2 \mathrm{~N}$ the upper limit of the institution's normal range). PET/CT was recommended but staging was not based on its result only. Other imaging was performed as clinically indicated. Staging was based according to the St Jude's/Murphy's and Ann Arbor classifications.

\section{Study therapy}

LMB2001 was a FAB (French-American-British)/LMB 96based protocol. Treatment was based on $S t$ Jude's/Murphy's stage. Therapeutic groups were defined as in previous LMB studies. ${ }^{9}$ All patients received a prephase of low-dose cyclophosphamide, vincristine, and prednisone (COP). Group B patients (stage III and non-CNS stage IV with marrow involvement $<25 \%$ ) received therapy similar to Group B on FAB/LMB96 with four cycles of chemotherapy. For all Group C patients, Group C1 patients (stage IV disease with marrow involvement $\geq 25 \%$ without CNS-positive disease) received high-dose methotrexate (HD MTX) $\left(8 \mathrm{~g} / \mathrm{m}^{2}\right)$ as previously given over 4 hours, whereas Group C3 patients (central nervous system [CNS]-positive) received HD MTX $\left(8 \mathrm{~g} / \mathrm{m}^{2}\right)$ over 24 hours..$^{12}$ Consecutive courses were given as soon as blood counts recovered and the patient's condition allowed, except for the maintenance courses, which were given at 28-day intervals.

From 2008, it was recommended to add rituximab (R) as an intravenous (IV) infusion $\left(375 \mathrm{mg} / \mathrm{m}^{2}\right)$ on day 1 of each chemotherapy course. Additionally, based on an unpublished prognostic analysis, patients with bulky mediastinal mass $(>10 \mathrm{~cm})$ and/or high LDH serum level $(>2 \mathrm{~N}$ on the Institution upper limit value), and/or lombo-aortic nodes were assigned to Group C1 regimen. Lastly, in 2010, the LMB-modified B/C chemotherapy with rituximab (total 6 doses) was recommended for all patients, consisting of two courses of RCOPADM Group B (cyclophosphamide, vincristine, prednisone, adriamycin, HD MTX $3 \mathrm{~g} / \mathrm{m}^{2}$ ) followed by two courses of RCYVE Group C (with high-dose cytarabine, and etoposide) and two courses of maintenance therapy with rituximab. Patients received two double intrathecal (DIT) only at day 2 of each COPADM course (Table 1).

Remission assessment was performed after the first consolidation course for Group B and after the second consolidation course for Group C and B/C. In patients with a residual mass by radiographic evaluation, an excision or biopsy for pathology review was recommended. However, as residual mass is frequent in PMLBL, if the therapy response was adequate and a biopsy was not performed, the patients were to remain on assigned treatment, and remission re-evaluated at the end of therapy. For Group B patients, if viable tumor cells were identified, the therapy was switched to the more intensive Group $\mathrm{C} 1$ regimen. $\mathrm{Pa}-$ tients with biopsy-proven viable tumor cells after the second consolidation course ((R)CYVE2) were considered to have primary refractory disease and evaluated as an event. No-treatment decisions were based on 18F-FDG $\mathrm{PET} / \mathrm{CT}$ results only, and 18F-FDG PET/CT were not reviewed for the purpose of this analysis. Patients with per- 

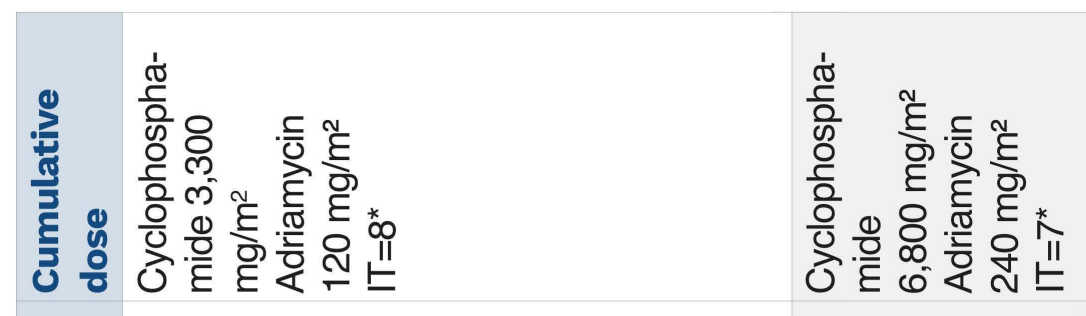

के चै

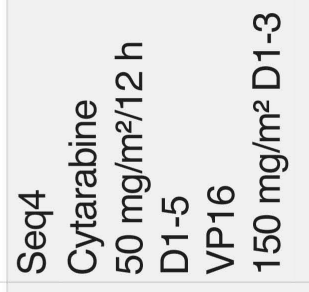

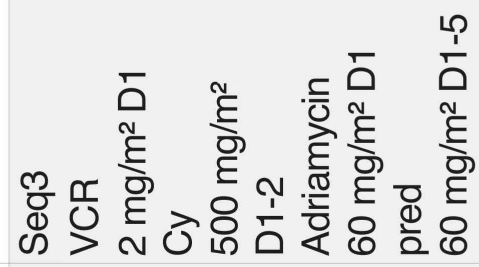
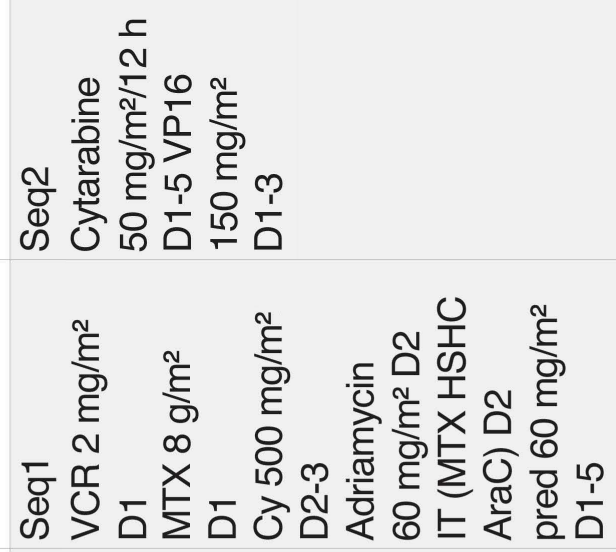

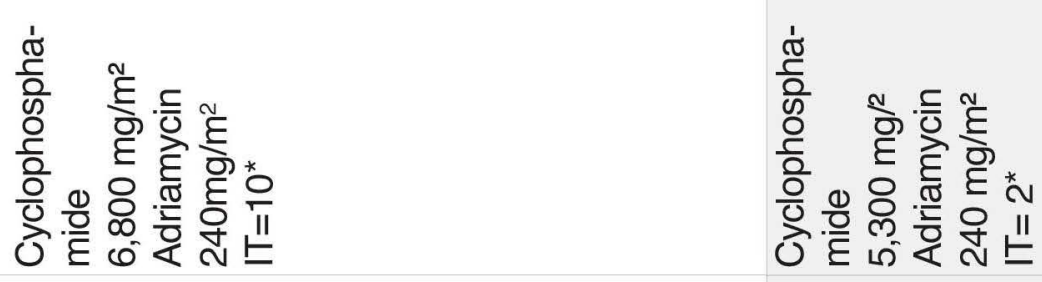

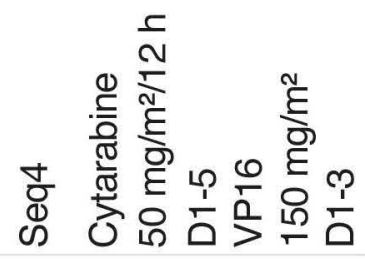

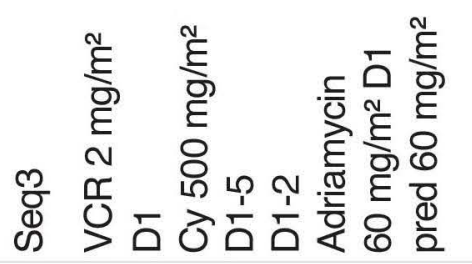

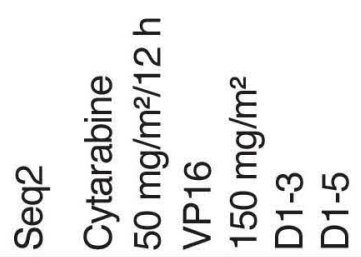

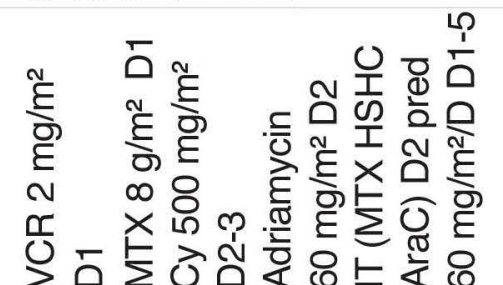

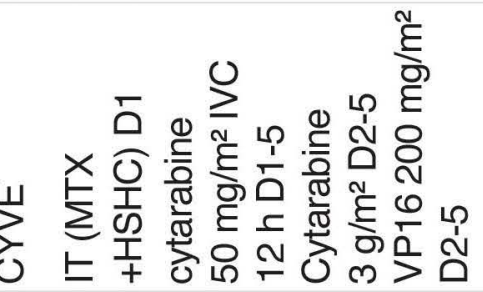

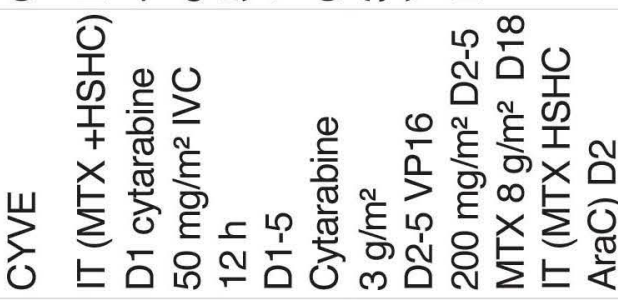

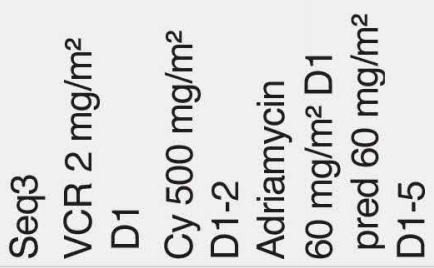

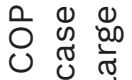

× $\subseteq \pi$

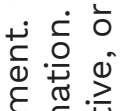

施

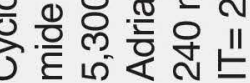

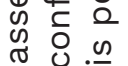

등

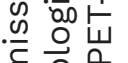

$\Phi, \frac{.0}{2}$

这然亭

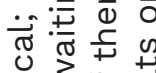

$\Phi \sum_{0} x_{0}$

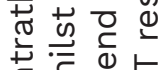

.

$\ddot{E}+$

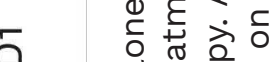

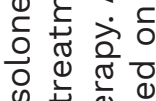

है

है

$\ddot{0}$ bo

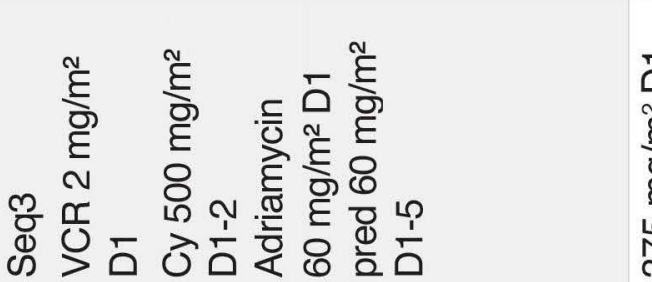

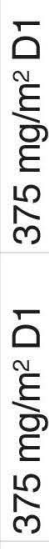

造:

बi $0 \begin{gathered}0 \\ 0\end{gathered}$

हैं

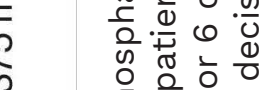

s.

응 후웜

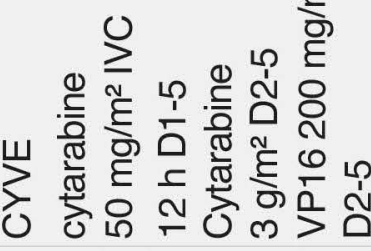

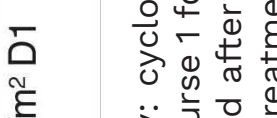

$\ddot{\overrightarrow{0}} \bar{\partial}$

बि

L L

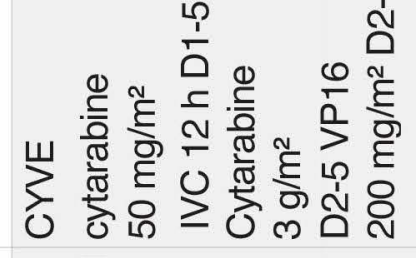

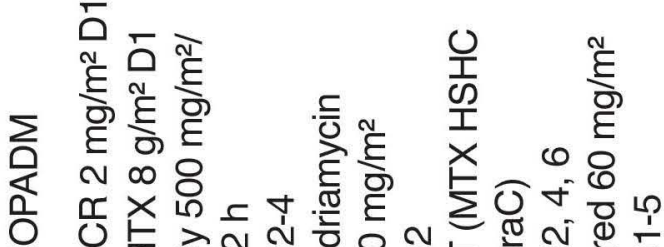

O

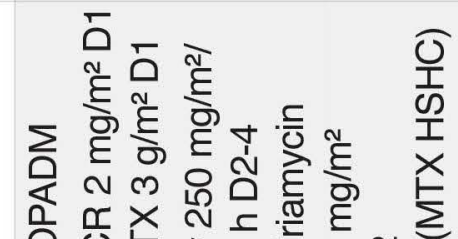

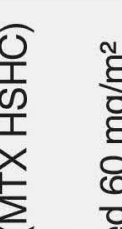

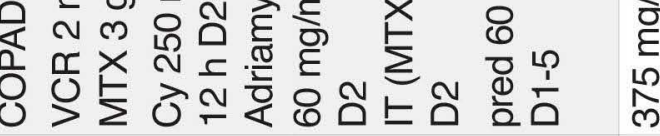

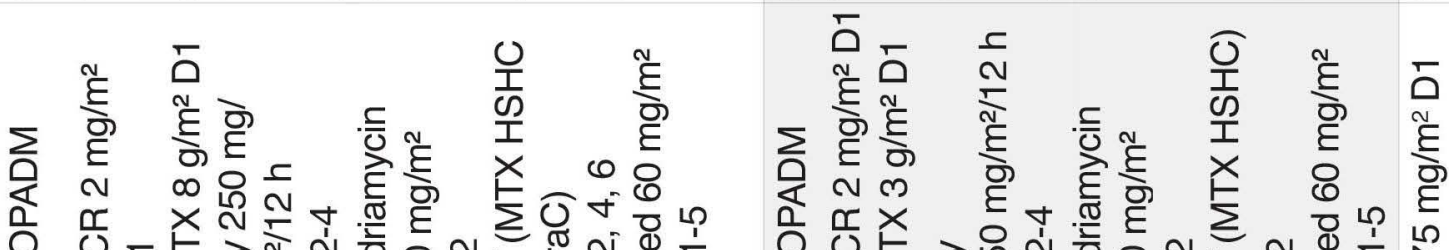

O

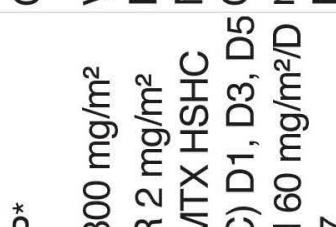

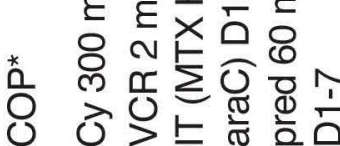

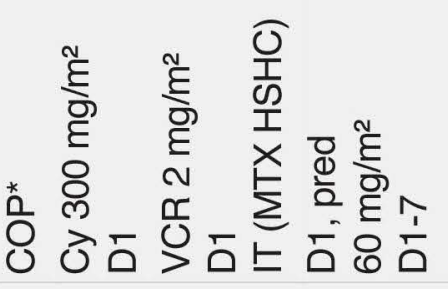

O

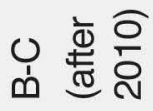


sistent disease after the end of treatment received different therapies, including additional RT, second-line chemotherapy, and consolidation with high-dose chemotherapy and autologous stem cell transplantation.

\section{Statistical analysis}

The primary efficacy endpoint was event-free survival (EFS), defined as the time from the start of chemotherapy to the first of the following events: biopsy-positive residual disease following (R)CYVE number 2 or at the end of therapy, progressive disease, relapse, second malignant neoplasm, and death of any cause. Patients without any of these events were censored at the date of the last follow-up. The secondary efficacy endpoint was overall survival (OS), defined as the time from the start of chemotherapy to death from any cause, or to the date of the last follow-up for alive patients. EFS and overall survival (OS) were estimated with the Kaplan-Meier method. ${ }^{13}$ The $95 \%$ confidence intervals $(95 \% \mathrm{Cl})$ of the survival rates were calculated with the Rothman method. ${ }^{14}$

\section{Results}

\section{Baseline characteristics}

Between 09/2001 and 03/2012, 42 of the 773 patients (5.4\%) with newly diagnosed B-NHL were registered as LBL with mediastinum as primary site in the prospective French LMB2001 study. Baseline characteristics are summarized in Table 2. The median age at diagnosis was 15 years (range, 8.4-18). There were 24 females (57\%). Thirty-three patients (79\%) had large mediastinal masses of $10 \mathrm{~cm}$ or more, 18 patients (43\%) had elevated LDH levels ( $>$ twice the institutional upper limit of the adult normal value), one patient had BM involvement and two patients were considered with CNS disease (one had facial paresthesia with normal magnetic resonance imaging but CSF could not be explored; one had asymptomatic epidural mass). No patient had positive CSF. In total, initial staging confirmed Ann Arbor stage II disease in 19 patients (45\%), stage III in one patient (2\%), and stage IV in 22 patients (52\%).

Table 2. Baseline characteristics of the patients.

\begin{tabular}{|c|c|c|c|}
\hline & $\begin{array}{l}\text { All patients } \\
\qquad \mathrm{N}=42\end{array}$ & $\begin{array}{c}\text { Patients treated } \\
\text { without rituximab } \\
\mathrm{N}=21\end{array}$ & $\begin{array}{l}\text { Patients treated } \\
\text { with rituximab } \\
\qquad=21\end{array}$ \\
\hline Female, N (\%) & $24(57)$ & $12(57)$ & $12(57)$ \\
\hline \multicolumn{4}{|l|}{ Age in years } \\
\hline Median (range) & $15(8-18)$ & $14(8-17)$ & $15(10-18)$ \\
\hline \multicolumn{4}{|l|}{ Distribution, N (\%) } \\
\hline$\geq 8-<12$ years & $4(10)$ & $3(14)$ & $1(5)$ \\
\hline$\geq 12-<15$ years & $17(40)$ & $9(43)$ & $8(38)$ \\
\hline$\geq 15-\leq 18$ years & $21(50)$ & $9(43)$ & $12(57)$ \\
\hline \multicolumn{4}{|l|}{ Ann Arbor stage, $\mathrm{N}(\%)$} \\
\hline II & $19(45)$ & $10(48)$ & $9(43)$ \\
\hline III & $1(2)$ & $0(0)$ & $1(5)$ \\
\hline IV & $22(52)$ & $11(52)$ & $11(52)$ \\
\hline Mediastinal tumor $\geq 10 \mathrm{~cm}$ diameter, $\mathrm{N}(\%)$ & $33(79)$ & $17(81)$ & $16(76)$ \\
\hline \multicolumn{4}{|l|}{ Sites of involvement, $\mathrm{N}(\%)$} \\
\hline Sub-diaphragmatic & $11(26)$ & $4(19)$ & $7(33)$ \\
\hline Bone marrow involvement & $1(2)$ & $0(0)$ & $1(5)$ \\
\hline Central nervous system & $2^{*}(5)$ & $0(0)$ & $2(10)$ \\
\hline $\mathrm{LDH}>2, \mathrm{~N}(\%)$ & $18(43)$ & $10(48)$ & $8(38)$ \\
\hline \multicolumn{4}{|l|}{ Initial therapeutic group } \\
\hline Group B & 19 & 16 & 3 \\
\hline Group B/C or C & 23 & 5 & 18 \\
\hline
\end{tabular}

*Central nervous system involvement consisted in: facial paresthesia with normal magnetic resonance imaging but the cerebrospinal fluid (CSF) could not be explored=1; asymptomatic epidural mass=1. LDH: lactate dehydrogenase. 
Figure 3. Events.

\begin{tabular}{|c|c|c|c|c|c|c|c|}
\hline $\begin{array}{l}\text { Patient } \\
\text { identification } \\
\text { number }\end{array}$ & $\begin{array}{c}\text { First line } \\
\text { therapy }\end{array}$ & $\begin{array}{l}\text { Site of } \\
\text { progression/ } \\
\text { relapse }\end{array}$ & $\begin{array}{l}\text { Time from } \\
\text { inclusion }\end{array}$ & $\begin{array}{l}2^{\text {nd }} \text { line } \\
\text { chemo- } \\
\text { therapy }\end{array}$ & $\begin{array}{c}\text { Radiation } \\
\text { therapy }\end{array}$ & $\begin{array}{l}\text { High dose } \\
\text { chemo- } \\
\text { therapy }\end{array}$ & $\begin{array}{l}\text { Patient status } \\
\text { at last news }\end{array}$ \\
\hline PMLBL1 & Group B, R- & mediastinum & $\begin{array}{l}\text { Progression } \\
\text { after CYVE1 } \\
3.4 \text { months* }\end{array}$ & $\begin{array}{l}\text { R-DHAP (3): } \\
\text { progression } \\
\text { R-ICE (2): } \\
\text { progression }\end{array}$ & No & No & $\begin{array}{c}\text { DOD, } \\
23 \text { months }\end{array}$ \\
\hline PMLBL2 & Group B, R- & mediastinum & $\begin{array}{l}\text { Progression } \\
\text { after CYM } \\
3.5 \text { months1 }\end{array}$ & $\begin{array}{l}\text { R-ICE (2): } \\
\text { progression } \\
\text { R-EPOCH (2): } \\
\text { progression }\end{array}$ & No & No & $\begin{array}{c}\text { DOD, } \\
9.3 \text { months }\end{array}$ \\
\hline PMLBL3 & Group B, R- & mediastinum & $\begin{array}{c}\text { Viable cells } \\
\text { in residual mass } \\
\text { after CYVE2 } \\
5.2 \text { months }\end{array}$ & R-ICE (2) & Yes & $\begin{array}{c}\text { BEAM and } \\
\text { ASCT }\end{array}$ & $\begin{array}{c}\mathrm{CR}, \\
6.9 \text { years }\end{array}$ \\
\hline PMLBL4 & Group B, R- & mediastinum & $\begin{array}{l}\text { Local relapse } \\
9.9 \text { months }\end{array}$ & $\begin{array}{l}\text { CYVE (2) } \\
\text { R (4) }\end{array}$ & No & No & $\begin{array}{c}\text { CR2, } \\
6.7 \text { years }\end{array}$ \\
\hline PMLBL5 & $\begin{array}{c}\text { Group B } \\
\text { switched to C } \\
\text { after COP, R+ }\end{array}$ & mediastinum & $\begin{array}{l}\text { Progression } \\
\text { after } \\
\text { R-COPADM1 } \\
0.6 \text { months }\end{array}$ & R-ICE (3) & Yes & $\begin{array}{c}\text { BEAM and } \\
\text { ASCT }\end{array}$ & $\begin{array}{c}\text { CR, } \\
11 \text { years }\end{array}$ \\
\hline
\end{tabular}

R: rituximab; BEAM: carmustine, etoposide, cytarabine, melphalan; DHAP: dexamethasone, high dose aracytin, cisplatinum; ICE: ifosfamide, etoposide, carboplatin; EPOCH: etoposide, prednisone, vincristine, cyclophosphamide, doxorubicin; ASCT: autologous stem cell transplantation; CR: complete remission; DOD: died of disease. ${ }^{*}$ Candidemia after prolonged aplasia followed by disease progression.

\section{Histological characteristics}

The national pathological review was done for 36 of 42 patients $(86 \%)$ and PMLBL diagnosis was confirmed for all except one case. For one case, a consensus diagnosis was not reached (differential diagnosis between PMLBL and grey zone lymphoma). The remaining six patients had a local pathological report compatible with the diagnosis of PMLBL.

All cases expressed B-cell marker CD20 and were negative for CD3. CD10, BCL6, MUM1, BCL2, CD23 expression were evaluated for 12 cases and showed staining in $21 \%, 73 \%$, $55 \%, 42 \%$, and $46 \%$ of cases, respectively. CD30 staining was weak and patchy found in $66 \%$ of cases. PDL1 expression was observed on tumor cells in $85 \%$ of cases. Finally, only one of 23 cases tested had EBER positivity by in situ hybridization.

\section{Treatment and response}

All patients received LMB-based chemotherapy: 19 patients were treated in Group B, 18 in Group C, and five with $\mathrm{LMB}-$ modified $\mathrm{B} / \mathrm{C}$. Twenty-one patients received rituximab (R+) (after 2008) while 21 did not (R-). Of the 40 (95\%) patients who were received COP therapy, 33 had at least a 20\% response. Two patients were transferred to Group $\mathrm{C}$ after COP therapy (1 R- ; $1 \mathrm{R}+$ ). Three patients had disease progression during therapy ( $2 \mathrm{R}-, 1 \mathrm{R}+)$. Among the
39 other patients, at remission assessment, two patients were in complete response (CR) while 37 had a residual mass on imaging, with a median size of $50 \mathrm{~mm}$ (range, 17135; data available for 30 patients). In total, 26 of 37 had biopsies, excisions or partial excisions: one had viable tumor cells (R-; tumor size: $68 \mathrm{~mm}$ after CYM1 vs. $108 \mathrm{~mm}$ at baseline) and for all other patients, the histology revealed complete necrosis. Thirty-eight patients (90\%, 95\% Cl: 77-97) were considered to have achieved CR (2 CR, 25 complete necrosis, and 11 residual mass not explored). Thirty-seven patients (88\%) had 18F-FDG PET/CT at remission assessment after a median of four chemotherapy courses (range, 3-6) of whom 26 (70\%) were considered positive according to current Cheson criteria. ${ }^{15}$ Among these 26 patients, four had further treatment failure, including one with histology positive residual disease, one with complete necrosis on biopsy, and two not biopsied (predictive positive value $=15 \% ; 95 \% \mathrm{Cl}: 4-35$ ). Among the 11 patients with negative 18F-FDG PET/CT, none had treatment failure (predictive negative value $=100 \%$; $95 \% \mathrm{Cl}: 72-$ 100).

\section{Outcome}

The median follow-up was 7.1 years (interquartile range, 5.8-11.1), 10.6 years for patients treated without rituximab, and 6.4 years for patients treated with rituximab. There 
were a total of five events (all local failures) (Table 3 ) with one insufficient response and viable cells in the residual mass (R-, patient obtained and remained in CR after R-ICE and BEAM, ASCT and radiotherapy), three disease progressions during treatment ( $2 \mathrm{R}-,, 1 \mathrm{R}+$ ) and one relapse ( $\mathrm{R}-$, patient obtained and remained in CR2). There was no second malignancy. Two of the three patients who progressed during treatment died of disease despite second-line therapy. The third one $(\mathrm{R}+)$ was switched to Group $\mathrm{C}$ after COP because of insufficient response and had disease progression after RCOPADM1 but remained in continuous first $C R$ after two courses of RICE, high-dose BEAM chemotherapy (carmustine, etoposide, cytarabine, and melphalan) and radiotherapy. In total, there were two deaths, the two following disease progression during therapy in R-patients. The probability of 5-year EFS was $88.1 \%$ (95\% Cl: $75.0-94.8$ ) in the whole cohort and $81.0 \%$ $(95 \% \mathrm{Cl}: 60.0-92.3)$ in R- patients and $95.2 \%(95 \% \mathrm{Cl}$ : 77.3-99.2) in $\mathrm{R}+$ patients corresponding to a hazard ratio of 0.24 (95\% Cl: $0.03-2.2$ ) (Figures 1 and $2 \mathrm{~A}$ ). The probability of 5-year OS was $95.2 \%$ (95\% Cl: $84.0-98.7)$ in the whole cohort and $90.5 \%$ (95\% Cl: 71.1-97.3) in R- patients) and $100 \%$ in $\mathrm{R}+$ patients (Figures 1 and $2 \mathrm{~B}$ ).

\section{Discussion}

In this prospective multicentric French LMB2001 study with intensive $L M B$ chemotherapy in addition to rituximab since 2008, pediatric and adolescent patients with PMLBL achieved excellent survivals. Five-year EFS and OS were 88.1\% (95\% Cl: $75.0-94.8)$ and $95.2 \%(95 \% \mathrm{Cl}: 84.0-98.7)$ for the whole population. The previous FAB/LMB 96 study in children and adolescents with PMLBL treated with Group B LMB chemotherapy reported a 5-year EFS and OS of $66 \%$ (95\% Cl: $49-78)$ and $73 \%(95 \% \mathrm{Cl}: 56-84) .{ }^{10}$ By comparison, in the current series, 21 patients with PMLBL were treated without rituximab (16 therapeutic Group B; 5 Group B/C or C) with 5-year EFS of $81.0 \%(95 \% \mathrm{Cl}$ : $60.0-$ 92.3). Thus, these current results without rituximab compare favorably with previous FAB/LMB 96 (although not statistically different). Although there is no easy explanation, we cannot exclude that more intense chemotherapy may be more effective (all events except one in the current series occurred in patients treated in Group B and percentage of patients initially treated with Group C or B/C is higher in the current series). It has been distinctly demonstrated in adult patients with PMLBL that the addition of rituximab improves the outcome (HR for events 0.3; 95\% Cl: $0.1-0.8) .{ }^{16}$ In the French LMB2001 study, the assessment of rituximab addition to LMB-based chemotherapy, which was not based on a randomized comparison but on a comparison of two periods, showed a similar HR ( HR for events 0.24 ; 95\% Cl: 0.03-2.2) with 5-year EFS of 81.0\% (95\% Cl: 60.0-92.3) without rituximab and 95.2\% (95\% Cl: 77.3-99.2) with rituximab.

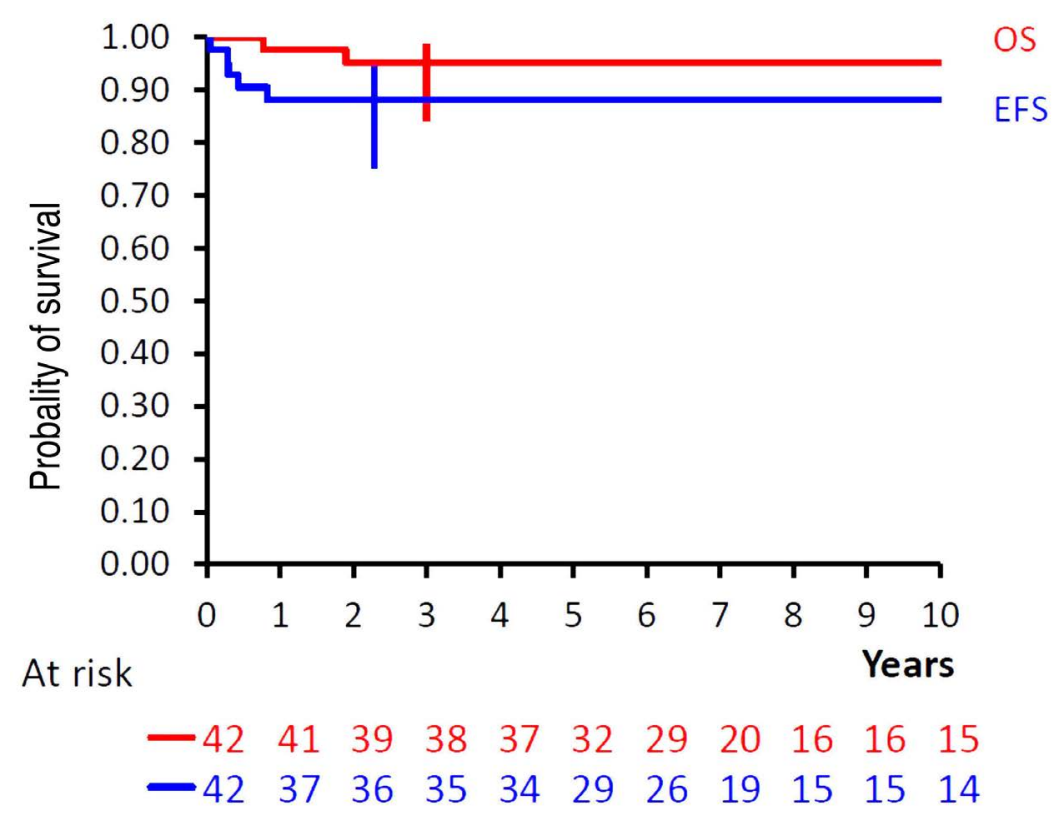

Figure 1. Kaplan Meier estimates of overall survival and eventfree survival. Vertical lines represent the Rothman 95\% confidence interval. EFS: event-free survival; OS: overall survival.
A

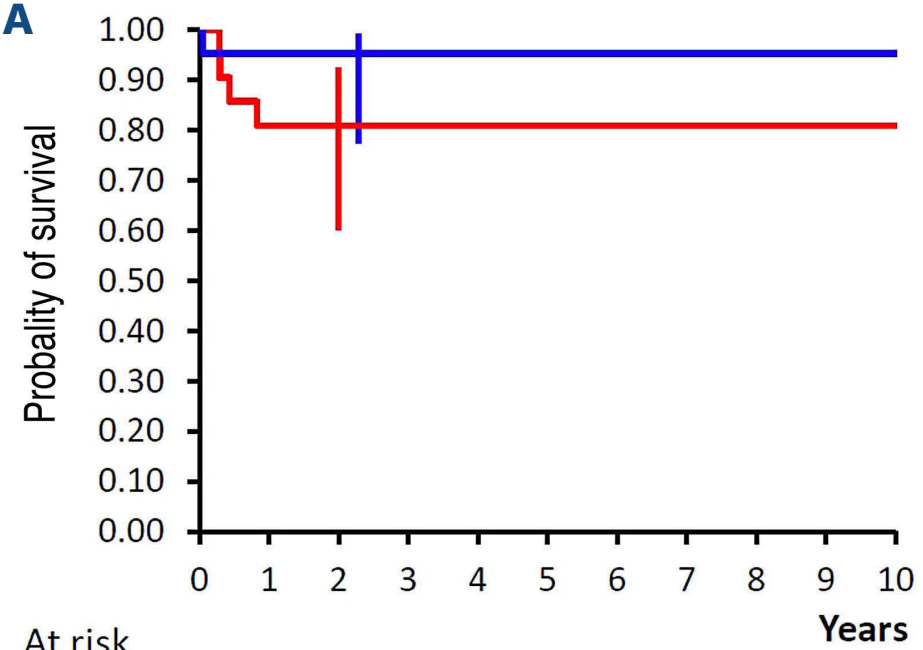

At risk

$\begin{array}{llllllllllll}21 & 17 & 17 & 17 & 17 & 16 & 15 & 11 & 10 & 10 & 10 & \text { No rituximab }\end{array}$ $\begin{array}{llllllllllll}-21 & 20 & 19 & 18 & 17 & 13 & 11 & 8 & 5 & 5 & 4 & \text { Rituximab }\end{array}$

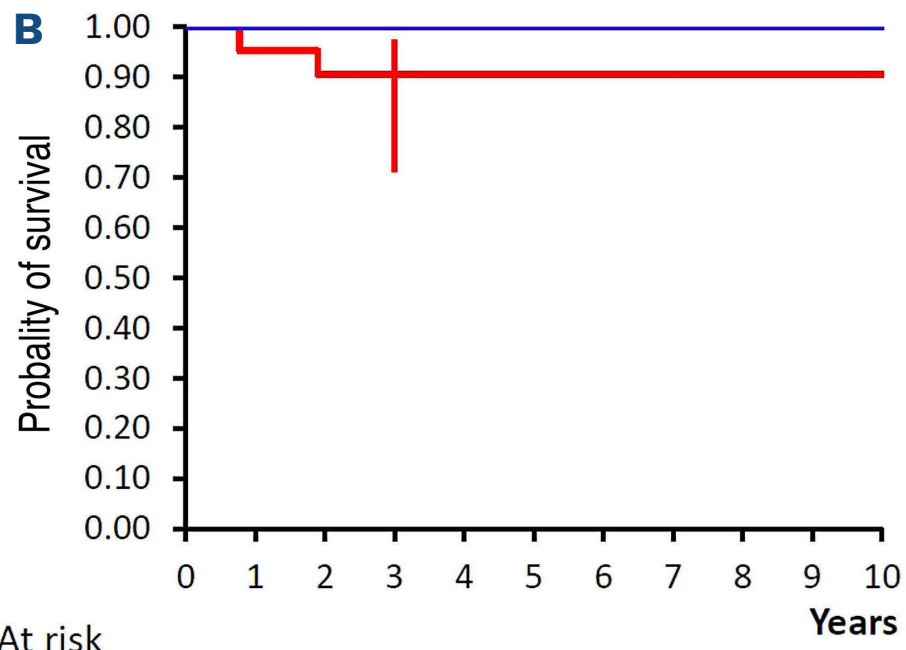

At risk

$\begin{array}{lllllllllll}-21 & 20 & 19 & 19 & 19 & 18 & 17 & 11 & 10 & 10 & 10\end{array}$ No rituximab Rituximab

Figure 2. Kaplan Meier estimates of event-free survival and overall survival according to rituximab administration. (A) Eventfree survival. (B) Overall survival. Vertical lines represent the Rothman 95\% confidence interval. 
These excellent results contrast with the results recently published with DA-EPOCH-R in 46 children and adolescents included in the international phase II Inter B-NHLritux 2010 study $^{7}$ (Table 4). Although the characteristics of the patients included in this study do not differ from those of the phase II Inter B-NHL-ritux 2010, 12 disease-related events were observed in the phase II, with 4-year EFS and OS of $69.6 \%(95 \% \mathrm{Cl}: 55.2-80.9)$ and $84.8 \%(95 \% \mathrm{Cl}: 71.8-$ 92.4), respectively, and three (6.5\%) parenchymal central nervous system relapses. All five disease-related events in the French LMB2001 study were local/mediastinal with no CNS relapses. Thus, CNS-directed therapy may be important in PMLBL and explains why we recommended since 2008 LMB B/C-modified regimen with rituximab, with some intrathecal therapy but also HD MTX and highdose cytarabine (AraC). Recently, a real-world study from the French LYSA group also reinforces the benefit of dose intense immuno-chemotherapy regimens in $\mathrm{PMLBL}^{17}$ : patients treated with R-ACVBP or R-CHOP14 achieved a better outcome than those treated with R-CHOP21 (progression-free survival of $89.4 \%$ vs. $74.7 \%$ ). R-ACVBP also included some CNS-directed therapies such as HD MTX and intrathecal in the majority of patients and CNS relapse rate was low $(2.9 \%)$ in this series.

By contrast with the pediatric phase II Inter-B-NHL ritux 2010 trial, outstanding survival for adult patients with PMLBL has been reported with DA-EPOCH-R in a singleinstitution, non-randomized phase II study, of 51 patients with EFS of $93 \%$ (95\% Cl: $81-98)$ and OS of $97 \%$ (95\% Cl: 81-99)..$^{18}$ In the same way, a large multicenter retrospective analysis reported on the outcome of pediatric and adult patients treated with DA-EPOCH-R for PMLBL. ${ }^{19}$ Survivals were not statistically different between pediatric and adult patients for both EFS ( $81.0 \%$ vs. $87.4 \%, P=0.338)$ and OS (90.7\% vs. $97.1 \%, P=0.170)$.

Clinically and pathologically, PMLBL disease in the pediatric population is indistinguishable from that seen in adult patients. Thus, the difference in outcome between the two main DA-EPOCH-R studies is therefore hard to explain although the methodology of these studies is very different (i.e., international vs. single-institution). Other registry-based or retrospective studies of children and adolescents with PMLBL treated with DA-EPOCH-R have been also reported. The BFM NHL group reported their multicentric experience between 2004 and 2019 with modified DA-EPOCH-R (addition of at least one intrathecal triple therapy and a cumulative doxorubicin dose limit at $\left.360 \mathrm{mg} / \mathrm{m}^{2}\right)(\mathrm{n}=67$ patients) or intensified chemotherapy B-NHL BMFO4 ( $n=29$ patients) and compared it retrospectively to the treatment regimen in the B-NHL BMF95 trial $\left(n=20\right.$ patients), both without rituximab. ${ }^{20}$ For patients treated with DA-EPOCH-R, the 5-year EFS and OS were 84\% (95\% Cl: $72-91)$ and 90\% (95\% Cl: 79-95), respectively. These results are intermediate between the outstanding results obtained in the phase II study in adult patients and the phase II Inter-B-NHL ritux 2010 in children (Table 4). However, despite the use of triple intrathecal, at relapse four of 11 patients treated with DAEPOCH-R had parenchymal CNS disease, strengthening the fact that it is necessary to improve CNS disease control in this pathology.

Pediatric-type B-NHL regimens, such as LMB and others, have higher acute toxicity when compared with DAEPOCH-R regimen. The DA-EPOCH-R phase II Inter-B-NHL ritux 2010 study in pediatric patients reported febrile neutropenia in $11 \%$ of courses and $46 \%$ of patients, infections grade $\geq 3$ in $4 \%$ of courses and $17 \%$ of patients and stomatitis grade $\geq 3$ in $3 \%$ of courses and $15 \%$ of patients. Although we did not register toxicity in the prospective French LMB2001 trial (but no toxic death occurred), other LMB-based chemotherapy trials with rituximab reported febrile neutropenia, infection grade $\geq 3$ and stomatitis grade $\geq 3$, in $92.6 \%, 58.6 \%$, and $79.6 \%$ of patients, respectively. ${ }^{21}$ However, management of long-term toxicity is also very important in this young population. The risks for significant long-term sequelae are relatively modest using

Table 4. Summary of R-DA-EPOCH studies and the LMB 2001 study.

\begin{tabular}{|c|c|c|c|c|c|c|c|c|}
\hline Study & Regimen & $\begin{array}{l}\text { Type of } \\
\text { study }\end{array}$ & Population & $\begin{array}{c}\mathrm{N} \text { of } \\
\text { patients }\end{array}$ & $\begin{array}{l}\text { Median } \\
\text { FU }\end{array}$ & $\begin{array}{l}\text { N of events } \\
\text { (CNS relapse) }\end{array}$ & $\begin{array}{c}\text { EFS, \% } \\
(95 \% \mathrm{CI})\end{array}$ & $\begin{array}{c}\text { OS, \% } \\
(95 \% \text { CI) }\end{array}$ \\
\hline $\mathrm{NCl}^{18}$ & DA-EPOCH-R & $\begin{array}{c}\text { Phase 2, } \\
\text { monocentric }\end{array}$ & Adults & 51 & 5 years & $3(0)$ & $\begin{array}{c}93 \\
(81-98)\end{array}$ & $\begin{array}{c}97 \\
(81-99)\end{array}$ \\
\hline $\mathrm{BFM}^{19}$ & DA-EPOCH-R & $\begin{array}{l}\text { Registry, } \\
\text { multicentric }\end{array}$ & Child/ado & 67 & 4 years & $11(4)$ & $\begin{array}{c}84 \\
(72-91)\end{array}$ & $\begin{array}{c}90 \\
(79-95)\end{array}$ \\
\hline $\begin{array}{l}\text { Inter B-NHL } \\
\text { ritux } 2010^{7}\end{array}$ & DA-EPOCH-R & $\begin{array}{l}\text { Phase 2, } \\
\text { multicentric }\end{array}$ & Child/ado & 46 & 5 years & $14(3)$ & $\begin{array}{c}70 \\
(55-81)\end{array}$ & $\begin{array}{c}85 \\
(72-92)\end{array}$ \\
\hline LMB 2001 & R-LMB & $\begin{array}{l}\text { Registry, } \\
\text { multicentric }\end{array}$ & Child/ado & 21 & 6 years & $1(0)$ & $\begin{array}{c}95 \\
(77-99)\end{array}$ & 100 \\
\hline LMB 2001 & LMB & $\begin{array}{l}\text { Registry, } \\
\text { multicentric }\end{array}$ & Child/ado & 21 & 10 years & $4(0)$ & $\begin{array}{c}81 \\
(60-92)\end{array}$ & $\begin{array}{c}90 \\
(71-97)\end{array}$ \\
\hline
\end{tabular}

Child/ado: children/adolescents; CI: confidence interval; EFS: event-free survival; FU: follow-up; OS: overall survival; DA-EPOCH-R: doseadjusted etoposide, doxorubicin, and cyclophosphamide with vincristine and prednisone plus rituximab. 
LMB chemotherapy backbone ${ }^{22}$ and the total cumulative dose of doxorubicin is limited and of $240 \mathrm{mg} / \mathrm{m}^{2}$ with the LMB B/C-modified combination (favorably compared with the DA-EPOCH-R in the Inter-B-NHL ritux 2010 study where $72 \%$ of patients received $\geq 300 \mathrm{mg} / \mathrm{m}^{2}$ doxorubicin and $\left.24 \% \geq 350 \mathrm{mg} / \mathrm{m}^{2}\right)^{7}$.

Although our study has some limitations, i.e., i) relative small series of 42 patients but it compares well with other published reports in this rare disease, ii) pathology review for only $85 \%$ of cases, iii) no randomized comparison between LMB chemotherapy only and LMB chemotherapy with rituximab, and iv) some differences during the study duration in terms of chemotherapy group recommendations, this was a prospective multicentric study, and we believe that these excellent results are important for the medical community of pediatric, adolescents, and young adults oncologists. Further prospective and international trials are required to confirm these results and define optimal treatment for patients with PMLBL (all ages included). Novel agents (e.g., NF-kB pathway inhibitors or anti-PD1 therapies combined or not with brentuximab-vedotin) may be required next to reduce chemotherapy intensity and improve outcome in this population. ${ }^{23}$

\section{Disclosures}

No conflicts of interest to disclose.

\section{Contributions}

$C P, A A, M E D$, and $V M-C$ conceived the study and oversaw the project; $A P, N G, N A, J M, S H, C P, J L-P, T L, C S, C P$ and $V M-C$ recruited patients; $A P, V M-C, A A, C P, J B$ and $M E D$ collected and assembled data; $A A$ performed statistical analysis; $M E D, A P, A A, J B, C P, V M-C$ analyzed and interpreted data; MED, $A P$ and VM-C wrote the manuscript. All authors approved the manuscript.

\section{Acknowledgments}

The authors thank Yasmina Oubouzar for data management. We thank all patients and their families for participating in the studies. We thank our colleagues in the hospitals and reference institutions who contributed to this study, for their care for the children and families, and the supplied data.

\section{Data-sharing statement}

The data that support the findings of this study are available on request from the corresponding author.

\section{References}

1. Swerdlow SH, Campo E, Pileri SA, et al. The 2016 revision of the World Health Organization classification of lymphoid neoplasms. Blood. 2016;127(20):2375-2390.

2. Burkhardt B, Zimmermann M, Oschlies I, et al. The impact of age and gender on biology, clinical features and treatment outcome of non-Hodgkin lymphoma in childhood and adolescence. Br J Haematol. 2005;131(1):39-49.

3. Martelli M, Di Rocco A, Russo E, Perrone S, Foà R. Primary mediastinal lymphoma: diagnosis and treatment options. Expert Rev Hematol. 2015;8(2):173-186.

4. Copie-Bergman C, Plonquet A, Alonso MA, et al. MAL expression in lymphoid cells: further evidence for MAL as a distinct molecular marker of primary mediastinal large B-cell lymphomas. Mod Pathol. 2002;15(11):1172-1180.

5. Alkhawtani RHM, Noordzij W, Glaudemans AWJM, et al. Lactate dehydrogenase levels and 18F-FDG PET/CT metrics differentiate between mediastinal Hodgkin's lymphoma and primary mediastinal B-cell lymphoma. Nucl Med Commun. 2018;39(6):572-578.

6. Melani C, Wilson WH, Roschewski M. What is the standard of care for primary mediastinal b-cell lymphoma; R-CHOP or DAEPOCH-R? Br J Haematol. 2019;184(5):836-838.

7. Burke GAA, Minard-Colin V, Aupérin A, et al. Dose-adjusted etoposide, doxorubicin, and cyclophosphamide with vincristine and prednisone plus rituximab therapy in children and adolescents with primary mediastinal B-cell lymphoma: a multicenter phase II trial. J Clin Oncol. 2021;39(33):3716-3724.

8. Patte C, Auperin A, Michon J, et al. The Société Française d'Oncologie Pédiatrique LMB89 protocol: highly effective multiagent chemotherapy tailored to the tumor burden and initial response in 561 unselected children with B-cell lymphomas and L3 leukemia. Blood. 2001;97(11):3370-3379.
9. Patte C, Auperin A, Gerrard M, et al. Results of the randomized international FAB/LMB96 trial for intermediate risk B-cell nonHodgkin lymphoma in children and adolescents: it is possible to reduce treatment for the early responding patients. Blood. 2007;109(7):2773-2780.

10. Gerrard M, Waxman IM, Sposto R, et al. Outcome and pathologic classification of children and adolescents with mediastinal large B-cell lymphoma treated with FAB/LMB96 mature B-NHL therapy. Blood. 2013;121(2):278-285.

11. Seidemann K, Tiemann M, Lauterbach I, et al. Primary mediastinal large B-cell lymphoma with sclerosis in pediatric and adolescent patients: treatment and results from three therapeutic studies of the Berlin-Frankfurt-Münster Group. J Clin Oncol. 2003;21(9):1782-1789.

12. Cairo MS, Gerrard M, Sposto R, et al. Results of a randomized international study of high-risk central nervous system B nonHodgkin lymphoma and B acute lymphoblastic leukemia in children and adolescents. Blood. 2007;109(7):2736-2743.

13. Kaplan EL, Meier P. Nonparametric estimation from incomplete observations. J Am Stat Assoc. 1958;53(282):457-481.

14. Rothman KJ. Estimation of confidence limits for the cumulative probability of survival in life table analysis. J Chronic Dis. 1978;31(8):557-560.

15. Cheson BD, Fisher RI, Barrington SF, et al. Recommendations for initial evaluation, staging, and response assessment of Hodgkin and non-Hodgkin lymphoma: the Lugano classification. J Clin Oncol. 2014;32(27):3059-3068.

16. Rieger M, Osterborg A, Pettengell R, et al. Primary mediastinal B-cell lymphoma treated with CHOP-like chemotherapy with or without rituximab: results of the Mabthera International Trial Group study. Ann Oncol. 2011;22(3):664-670.

17. Camus V, Rossi C, Sesques $P$, et al. Outcomes after first-line 
immunochemotherapy for primary mediastinal B cell lymphoma patients: a LYSA study. Blood Adv. 2021;5(19):3862-3872.

18. Dunleavy K, Pittaluga S, Maeda LS, et al. Dose-adjusted EPOCHrituximab therapy in primary mediastinal B-cell lymphoma. $\mathrm{N}$ Engl J Med. 2013;368(15):1408-1416.

19. Giulino-Roth L, O'Donohue T, Chen Z, et al. Outcomes of adults and children with primary mediastinal B-cell lymphoma treated with dose-adjusted EPOCH-R. Br J Haematol. 2017;179(5):739-747.

20. Knörr F, Zimmermann M, Attarbaschi A, et al. Dose-adjusted EPOCH-Rituximab or intensified B-NHL therapy for pediatric primary mediastinal large B-cell lymphoma. Haematologica.
2021;106(12):3232-3235.

21. Minard-Colin $V$, Aupérin A, Pillon $M$, et al. Rituximab for highrisk, mature B-cell non-Hodgkin's lymphoma in children. N Engl J Med. 2020;382(23):2207-2219.

22. Ehrhardt MJ, Chen Y, Sandlund JT, et al. Late health outcomes after contemporary Llymphome Malin de Burkitt therapy for mature B-cell non-Hodgkin lymphoma: a report from the Childhood Cancer Survivor Study. J Clin Oncol. 2019;37(28):2556-2570.

23. Armand P, Rodig S, Melnichenko V, et al. Pembrolizumab in relapsed or refractory primary mediastinal large B-cell lymphoma. J Clin Oncol. 2019;37(34):3291-3299. 